\title{
Open Futures in the Foundations of Propositional Logic
}

\author{
James W. Garson
}

Even in the analysis of Greek and Latin (where the 'future' like the 'present' and the 'past' is realized inflexionally), there is some reason to describe the 'future tense' as partly modal.

John Lyons (1968, p. 306)

\begin{abstract}
This chapter weaves together two themes in the work of Nuel Belnap. The earlier theme was to propose conditions (such as conservativity and uniqueness) under which logical rules determine the meanings of the connectives they regulate. The later theme was the employment of semantics for the open future in the foundations of logics of agency. This chapter shows that on the reasonable criterion for fixing meaning of a connective by its rule governed deductive behavior, the natural deduction rules for classical propositional logic do not fix the interpretation embodied in the standard truth tables, but instead express an open future semantics related to Kripke's possible worlds semantics for intuitionistic logic, called natural semantics. The basis for this connection has already been published, but this chapter reports new results on disjunction, and explores the relationships between natural semantics and supervaluations. A possible complaint against natural semantics is that its models may disobey the requirement that there be no branching in the past. It is shown, however, that the condition may be met by using a plausible reindividuation of temporal moments. The chapter also explains how natural semantics may be used to locate what is wrong with fatalistic arguments that purport to close the door on a open future. The upshot is that the open future is not just essential to our idea of agency, it is already built right into the foundations of classical logic.
\end{abstract}

\footnotetext{
J. W. Garson $(\varangle)$

Philosophy Department, University of Houston, Houston, TX 77204-3004, USA

e-mail: garson@Central.UH.EDU
} 


\section{Introduction}

This chapter weaves together two themes in the work of Nuel Belnap. The earlier theme, launched in "Tonk, Plonk, and Plink" (1962), was to propose conditions under which logical rules determine the meanings of the connectives they regulate. The later theme was the employment of semantics for the open future in the foundations of logics of agency. The first theme leads to the second in the following way. Consider the natural deduction rules for standard propositional logic, which by the lights of "Tonk, Plonk and Plink" successfully define meanings for the connectives $\&, \rightarrow$, $\sim$, and $v$. What are the meanings so assigned? Is there a way to give a semantical characterization of what the demand that a connective obey its rules says about the connective's meaning? It will be shown here that on at least one reasonable criterion for fixing meaning of a connective by its rule governed deductive behavior, the natural deduction rules for (classical) propositional logic do not fix the interpretation embodied in the standard truth tables, but instead express an open future semantics related to Kripke's S4 possible worlds semantics for intuitionistic logic. Part of the basis for this connection has already been worked out (Garson 1990, 2001). This chapter reports new results on disjunction, and explores the relationships between this open future semantics and supervaluations. The upshot is that the semantics actually expressed by the standard natural deduction rules for propositional logic is a semantics for an open future. Since that semantics is the one the rules of propositional logic actually fix, it is reasonable to think that that is the interpretation of the connectives that we have (secretly?) employed all along. It is not just that the conception of an open future is built into our idea of agency, it is already found in the foundations of classical logic. It will be no surprise then, when this interpretation shows itself to be useful for locating what is wrong with fatalistic arguments that attempt to close the door on a open future.

\section{What Rules Express}

The idea of a sentence (or group of sentences) expressing a condition on a model should be familiar. For example, the sentence $\exists x \exists y \sim x=y$ expresses that the domain of a model contains at least two objects, for $\exists x \exists y \sim x=y$ is true on a model exactly when its domain meets that condition. So in general, sentence A expresses property $\mathrm{P}$ of models iff $\mathrm{A}$ is true on a model exactly when that model has property $\mathrm{P}$.

How should this idea be generalized to the case of what is expressed by a rule of logic? The generalization we are seeking involves two dimensions. The first has to do with how we conceive of logic rules. It is natural to think of a traditional logical rule as a function taking one or more sentence (forms) into a new sentence (form). However, it will be important for this chapter to accommodate natural deduction rules, for they have expressive powers that traditional rules lack. Natural deduction (ND) systems allow the introduction of ancillary hypotheses and subproofs. In that case, a rule amounts to a function that takes an argument or set of arguments into a new 
argument. For example, the rule of Conditional Proof takes the argument H, A / C (which asserts that $\mathrm{C}$ follows from the ancillary hypothesis $\mathrm{A}$ along with other hypotheses $\mathrm{H}$ ) to the new argument $\mathrm{H} / \mathrm{A} \rightarrow \mathrm{C}$ (which asserts that the conditional $\mathrm{A} \rightarrow \mathrm{C}$ follows from hypotheses $\mathrm{H}$ ).

The second aspect of the generalization concerns how to define what we mean by a model of a rule. A model of a sentence is one where the sentence is true. However, we have decided that a rule is a function that takes an argument or arguments to a new argument. So what does it mean to say that a rule holds in a model? One answer is to say that a model satisfies an argument iff whenever the model makes its premises true it makes the conclusion true. Then a model of a rule would be any model that preserves satisfaction of its arguments. However, this idea is not sufficiently general. There are rules (such as Necessitation in modal logic and Universal Generalization in predicate logic) that do not preserve satisfaction. Therefore, preservation of validity rather than preservation of truth should be used to define what a rule expresses. The upshot will be that the definition of what a rule expresses has it that a ND rule expresses a property $\mathrm{P}$ iff $\mathrm{P}$ holds exactly when the rule preserves validity. The following series of definitions implements this basic idea.

Let an argument $\mathrm{H} / \mathrm{C}$ be composed of a (possibly empty) set of wffs $\mathrm{H}$ (called the hypotheses), and a single wff $\mathrm{C}$ called the conclusion. Let a valuation be any function from the set of wffs of propositional logic (PL) to the set $\{t, f\}$ of truthvalues such that it assigns $\mathrm{f}$ to at least one wff. (The last requirement ensures that valuations be minimally consistent.) Valuation $v$ satisfies a set $H$ of wffs $H$ (written $\mathrm{v}(\mathrm{H})=\mathrm{t})$ iff $\mathrm{v}(\mathrm{B})=\mathrm{t}$ for each member $\mathrm{B}$ of $\mathrm{H}$. Valuation $\mathrm{v}$ satisfies an argument $\mathrm{H} \vdash \mathrm{C}$ iff whenever $\mathrm{v}(\mathrm{H})=\mathrm{t}, \mathrm{v}(\mathrm{C})=\mathrm{t}$. Let a model $\mathrm{V}$ be any set of valuations. (The valuations in $\mathrm{V}$ play the role of possible worlds in models for modal logic.) An argument $\mathrm{H} \vdash \mathrm{C}$ is $\mathrm{V}$-valid iff it is satisfied by every member of $\mathrm{V}$. A set $\mathrm{V}$ is a model of a ND rule iff whenever its inputs are V-valid then so is its output. An ND-rule R expresses property $\mathrm{P}$ iff $\mathrm{V}$ is a model of $\mathrm{R}$ exactly when property $\mathrm{P}$ holds of $\mathrm{V}$.

\section{What Intuitionistic Logic Expresses}

With the notion of what a rule expresses in hand, we can explore the conditions under which a given collection of rules defines the meaning of the connectives they govern. When a system of rules $\mathrm{S}$ expresses a property $\|\mathrm{S}\|$ that qualifies as truth conditions for its connectives, it is reasonable to claim that $\|S\|$ gives the meanings defined by those rules. When this occurs, I call $\|S\|$ the natural semantics for S. Garson (2001) reports results on the natural semantics expressed by ND rules for intuitionistic logic, which will be briefly reviewed here. The concern in this chapter will be to extend these results to standard propositional logic with special emphasis on the interpretation of disjunction. It will then be possible to reflect on the relationships between this semantics and models for an open future.

We will assume that the ND systems discussed in this chapter obey the following structural rules. When argument $\mathrm{H} / \mathrm{C}$ is provable for a given system $\mathrm{S}$ we write: 
' $\mathrm{H} \vdash_{\mathrm{S}} \mathrm{C}$ ', but we suppress the subscript $\mathrm{S}$ when it is clear what $\mathrm{S}$ is from the context. Therefore the symbol ' $\%$ ' is in the object language and ' $\vdash$ ' in the metalanguage.

$$
\begin{array}{ll}
\text { The Structural Rules for Natural Deduction } \\
\begin{array}{ll}
\text { (Hypothesis) } & \mathrm{H} \vdash \mathrm{C}, \text { provided } \mathrm{C} \text { is in } \mathrm{H} . \\
\text { (Reiteration) } & \frac{\mathrm{H} \vdash \mathrm{C}}{\mathrm{H}, \mathrm{A} \vdash \mathrm{C}} \\
\text { (Restricted Cut) } & \mathrm{H} \vdash \mathrm{A} \\
& \frac{\mathrm{H}, \mathrm{A} \vdash \mathrm{C}}{\mathrm{H} \vdash \mathrm{C}}
\end{array}
\end{array}
$$

(Permutation and Contraction come for free, since $\mathrm{H}$ is taken to be set.) Natural deduction rules for a system PL for propositional logic follow.

$$
\begin{aligned}
& \begin{array}{llll}
\mathrm{S} \&: & (\& \mathrm{In}) & (\& \text { Out }) & \\
& \mathrm{H} \vdash \mathrm{A} & \mathrm{H} \vdash \mathrm{A} \& \mathrm{~B} & \\
& \frac{\mathrm{H} \vdash \mathrm{B}}{\mathrm{H} \vdash \mathrm{A} \& \mathrm{~A}} & \mathrm{H} \vdash \mathrm{A} & \mathrm{H} \vdash \mathrm{B}
\end{array} \\
& \mathrm{S} \rightarrow:(\rightarrow \text { In }) \quad(\rightarrow \text { Out }) \\
& \mathrm{H}, \mathrm{A} \vdash \mathrm{B} \quad \mathrm{H} \vdash \mathrm{A} \\
& \overline{\mathrm{H} \vdash \mathrm{A} \rightarrow \mathrm{B}} \quad \frac{H \vdash A \rightarrow B}{\mathrm{H} \vdash \mathrm{B}} \\
& \mathrm{S} \sim \mathrm{:} \quad(\sim \mathrm{In}) \quad(\sim \text { Out }) \\
& \mathrm{H}, \mathrm{A} \vdash \mathrm{B} \quad \mathrm{H}, \sim \mathrm{A} \vdash \mathrm{B} \\
& \frac{\mathrm{H}, \mathrm{A} \vdash \sim \mathrm{B}}{\mathrm{H} \vdash \sim \mathrm{A}} \quad \frac{\mathrm{H}, \sim \mathrm{A} \vdash \sim \mathrm{B}}{\mathrm{H} \vdash \mathrm{A}} \\
& \text { Sv: (v In) (v Out) } \\
& \mathrm{H} \vdash \mathrm{A} \quad \mathrm{H} \vdash \mathrm{B} \quad \mathrm{H} \vdash \mathrm{A} \vee \mathrm{B} \\
& \overline{\mathrm{H} \vdash \mathrm{AvB}} \quad \overline{\mathrm{H} \vdash \mathrm{AvB}} \quad \mathrm{H}, \mathrm{A} \vdash \mathrm{C} \\
& \frac{\mathrm{H}, \mathrm{B} \vdash \mathrm{C}}{\mathrm{H} \vdash \mathrm{C}}
\end{aligned}
$$

For the purposes of this chapter, it is best to begin with an intuitionistic logic I $\neg$ that lacks disjunction. So let the system I $\neg$ be identical to PL save that the connective $\mathrm{v}$, and the rules for $\mathrm{v}$ are missing, and ( Out) is replaced with the following rule (EFQ) for ex falso quodlibet:

$$
\begin{aligned}
& (\mathrm{EFQ}) \\
& \mathrm{H} \vdash \mathrm{B} \\
& \mathrm{H} \vdash \sim \mathrm{B} \\
& \mathrm{H} \vdash \mathrm{A}
\end{aligned}
$$


Results of Garson (1990 and 2001) are sufficient to show that I $\neg$ expresses the following truth conditions for the connectives $\&, \rightarrow$, and $\sim$. (For a more unified treatment, see Sect. 6.4 of Garson (2013). Here the truth conditions are expressed as properties of a model $\mathrm{V}$, the metavariables ' $\mathrm{v}$ ' and ' $\mathrm{v}$ ' are understood to range over $\mathrm{V}$, and the relation $\leq$ is defined by $($ Def $\leq)$.

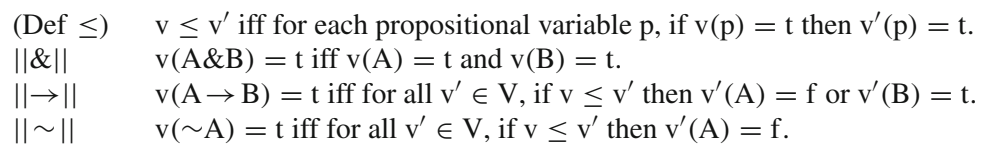

Note that the interpretation for $\&$ induced by $\mathrm{I} \neg$ is the standard one, while in the case of $\|\rightarrow\|$, and $\|\sim\|$ we have truth conditions reminiscent of Kripke's S4 semantics for intuitionistic logic. In that semantics, a model $<\mathrm{W}, \subseteq$, a $>$ is a triple, where $\mathrm{W}$ is a non-empty set (of possible worlds), $\mathbf{a}$ is an assignment function taking each world $\mathbf{w}$ in $W$ and propositional variable $p$, into a truth value $\mathbf{a}_{\mathbf{w}}(\mathrm{p})$, and $\subseteq$ is a transitive and reflexive relation over $\mathrm{W}$, such that for $\mathbf{w}$ and $\mathbf{w}^{\prime}$ in $\mathrm{W}$, if $\mathbf{w} \subseteq \mathbf{w}^{\prime}$, then if $\mathbf{a}_{\mathbf{w}}(\mathrm{p})=\mathrm{t}$ then $\mathbf{a}_{\mathbf{w}^{\prime}}(\mathrm{p})=\mathrm{t}$, for each propositional variable $\mathrm{p}$. In this semantics, the relation $\subseteq$ is understood to represent the historical process of the addition of new mathematical results by the community of mathematicians.

Let $\|\mathrm{I} \neg\|$ be the semantics expressed by $\mathrm{I} \neg$, that is, the conjunction of $\|\&\|,\|\rightarrow\|$, and $\|\sim\|$. It is a straightforward matter to show Garson (2013) that any model V that obeys $\|\mathrm{I} \neg\|$ is isomorphic to a corresponding Kripke model $<\mathbf{W}, \subseteq$, a $>$ where W is simply $\mathrm{V}, \subseteq$ is the relation $\leq$ defined by (Def $\leq$ ), and $\mathbf{a}_{\mathbf{v}}(\mathrm{p})=\mathrm{t}$ iff $\mathrm{v}(\mathrm{p})=\mathrm{t}$. Therefore, the condition expressed by $\mathrm{I} \neg$ is that the connectives $\&, \rightarrow$, and $\sim$ obey their corresponding truth behavior in Kripke semantics for intuitionistic logic. An important lemma in the proof of this result follows for $\mathrm{v}$ and $\mathrm{v}^{\prime}$ in $\mathrm{V}$.

\section{Persistence Lemma.}

$\mathrm{v} \leq \mathrm{v}^{\prime}$ iff for a every wff $\mathrm{A}$, if $\mathrm{v}(\mathrm{A})=\mathrm{t}$ then $\mathrm{v}^{\prime}(\mathrm{A})=\mathrm{t}$.

This means that the relation $\leq$ holds for $\mathrm{v}$ and $\mathrm{v}^{\prime}$ when the set of sentences true in $\mathrm{v}$ is a subset of those true in $v^{\prime}$. So the possible worlds (or valuations) can be understood as representing states of mathematical knowledge expressed as consistent sets of (atomic and complex) sentences, and $\mathrm{v} \leq \mathrm{v}^{\prime}$ holds when $\mathrm{v}^{\prime}$ represents a (possible) extension of mathematical knowledge from what is reflected in $\mathrm{v}$.

The fact that $\mathrm{I} \neg$ expresses the above truth conditions is a powerful result, for we know that any model for the rules of $\mathrm{I} \neg$ will have to give the connectives these interpretations. The rules of $\mathrm{I} \neg$ exactly determine the $\mathrm{S} 4$ reading for the connectives. It is a simple matter to exploit this finding to obtain completeness results for $\mathrm{I} \neg$ with respect to $\|\mathrm{I} \neg\|$. In fact, there is a general result that whenever a system $\mathrm{S}$ expresses a natural semantics $\|\mathrm{S}\|$, then $\mathrm{S}$ must be complete with respect to $\|\mathrm{S}\|$. (See Chapter 12 of Garson (2013).) 


\section{Open Future Semantics}

It is a fundamental presupposition of a theory of action that there are some things that lie within, and some that lie outside, our control. The events of the past are settled, and nothing we can do will change them. Therefore, the sentences that report those events are not the "targets" of agency. If sentence A reports an event in the past, then the claim that person p brings it about (now) that $\mathrm{A}$ is automatically false. There are also sentences reporting future events that defy agency as well, for example, tautologies and contradictions. However, within the class of future contingent sentences A, there are at least some where we have control over the events they describe, so that it would be true to say that person $\mathrm{p}$ brings it about that $\mathrm{A}$. There is a strong intuition that when I act to bring about A, whether $\mathrm{A}$ is true or not is up to me. Therefore both $\mathrm{A}$ and $\sim$ A must have been possible before I acted. So, the future offers me a collection of possibilities, which we represent in a tree, with my choices at each of the branch points. An essential intuition related to this vision is that some future contingent sentences are not yet settled, though they may be at a future time. Therefore, if I act in a way that settles A, then neither A nor $\sim$ A could have been settled before I act.

Some philosophers claim that the asymmetry between past and future reflected in our ideas about action is actually bogus, and there is only one temporal stream, where both past and future are fixed. Others insist that our freedom to choose is an illusion. But even if one had good reasons for accepting such a views, it wouldn't change the fact that a natural model for the way we actually do understand agency treats future possibilities as a forward facing tree with our choices at the branch points. Whatever the fate of the concept of agency, its pervasive use motivates the development of a semantics that does justice to its basic intuitions.

The intuitionistic semantics ||I $\neg||$ built into propositional logic has a natural application to this project. Consider a language whose atomic sentences report dated events. That will mean that atomic sentences are temporally closed in the sense that their truth-values are insensitive to their time of evaluation. A possible world (or valuation) $\mathrm{v}$ assigns $\mathrm{t}$ to those sentences that report events that are so far settled; so when A reports a past event, or something in the future that is inescapable (for example, something tautologous), v ought to assign it the value t. The relation $\leq$ then keeps track of the way in which valuations are extended as the passage of time settles more and more sentences. So $\mathrm{v} \leq \mathrm{v}^{\prime}$, indicates that $\mathrm{v}^{\prime}$ is a possible extension of the sentences that are settled in $\mathrm{v}$, that is, $\mathrm{v}^{\prime}$ is one of the ways that choices might be eventually be settled given the choices available in $\mathrm{v}$.

To capture these ideas formally, some definitions are in order. We will say that $\mathrm{A}$ is settled true at valuation $\mathrm{v}$ (written: $\mathrm{v}(\mathrm{A})=\mathrm{T}$ ) iff the value of $\mathrm{A}$ is $\mathrm{t}$ in every extension of $\mathrm{v}$ (including $\mathrm{v}$ itself). Similarly, $\mathrm{A}$ is settled false at $\mathrm{v}$ (written: $\mathrm{v}(\mathrm{A})=\mathrm{F}$ ) iff the value of $\mathrm{A}$ is $\mathrm{f}$ (untrue) in every extension of $\mathrm{v}$. If $\mathrm{A}$ is settled true or settled false at $\mathrm{v}$ then we say $\mathrm{A}$ is settled, and if $\mathrm{A}$ is not settled we call it unsettled (written $\mathrm{v}(\mathrm{A})=\mathrm{U})$. So, we have the following official definitions: 
(DefT) $\mathrm{v}(\mathrm{A})=\mathrm{T}$ iff for all $\mathrm{v}^{\prime} \in \mathrm{V}$, if $\mathrm{v} \leq \mathrm{v}^{\prime}$, then $\mathrm{v}^{\prime}(\mathrm{A})=\mathrm{t}$.

(DefF) $\mathrm{v}(\mathrm{A})=\mathrm{F}$ iff for all $\mathrm{v}^{\prime} \in \mathrm{V}$, if $\mathrm{v} \leq \mathrm{v}^{\prime}$, then $\mathrm{v}^{\prime}(\mathrm{A})=\mathrm{f}$.

$($ DefU) $\mathrm{v}(\mathrm{A})=\mathrm{U}$ iff neither $\mathrm{v}(\mathrm{A})=\mathrm{T}$ nor $\mathrm{v}(\mathrm{A})=\mathrm{F}$.

Some useful facts about these definitions are worth noting.

$$
(\text { Fact } 1) \mathrm{v}(\mathrm{A})=\mathrm{T} \text { iff } \mathrm{v}(\mathrm{A})=\mathrm{t} .
$$

The proof of (Fact 1 ) is by the Persistence Lemma and the reflexivity of $\leq$. It says that being true $(\mathrm{t})$ and settled true $(\mathrm{T})$ are extensionally equivalent.

$$
(\text { Fact 2) } \mathrm{v}(\sim \mathrm{A})=\mathrm{t} \text { iff } \mathrm{v}(\mathrm{A})=\mathrm{F} \text {. }
$$

(Fact 2) follows from the (DefF), and the truth condition $\|\sim\|$. It allows a quick calibration of the difference between classical negation and intuitionistic negation. For classical negation $\sim A$ 's being true entails that $A$ has the value $f$, while in the intuitionistic semantics, the truth of $\sim \mathrm{A}$ entails the stronger claim that $\mathrm{A}$ is settled false $(\mathrm{F})$.

$$
(\text { Fact } 3) \mathrm{v}(\mathrm{A})=\mathrm{U} \text { iff } \mathrm{v}(\mathrm{A})=\mathrm{f} \text { and } \mathrm{v}(\sim \mathrm{A})=\mathrm{f} \text {. }
$$

The proof of (Fact 3 ) follows from the definition of U, (Fact 1), and $\|\sim\|$. The idea is that an unsettled sentence is simply one for which neither it nor its negation is true. In light of (Fact 1), this makes sense, for when A or $\sim \mathrm{A}$ are true they are settled true, and by (Fact 2) when $\sim \mathrm{A}$ is settled true, A must be settled false. Therefore for A to be unsettled, neither A nor $\sim \mathrm{A}$ can be true. The upshot is that the intuitionistic semantics has the resources to capture the idea that some sentences are unsettled and so count as possible "targets" for agency.

$($ Fact 4$) \mathrm{v}(\mathrm{A}) \neq \mathrm{F}$ iff $\mathrm{v}(\mathrm{A})=\mathrm{T}$ if $\mathrm{A}$ is settled at $\mathrm{v}$.

(Fact 4) follows because settled true, settled false, and unsettled are exhaustive categories. Therefore, $\mathrm{v}(\mathrm{A})$ is not $\mathrm{F}$ if and only if $\mathrm{v}(\mathrm{A})$ is $\mathrm{U}$ or $\mathrm{T}$, or to put it another way, $\mathrm{v}(\mathrm{A})=\mathrm{T}$ if $\mathrm{A}$ is settled at $\mathrm{v}$. So when $\mathrm{v}(\mathrm{A}) \neq \mathrm{F}$ we might say that $\mathrm{A}$ is quasi-true at $\mathrm{v}$, and write $\mathrm{v}(\mathrm{A})=\mathrm{qT}$ to indicate that $\mathrm{A}$ is settled true at $\mathrm{v}$, if settled there at all. Then Fact (4) entails (Fact 5).

$$
(\text { Fact } 5) \mathrm{v}(\mathrm{A}) \neq \mathrm{F} \text { iff } \mathrm{v}(\mathrm{A})=\mathrm{qT} \text {. }
$$




\section{What Propositional Logic Expresses}

We have shown that the framework for an open future semantics is expressed by intuitionistic logic $\mathrm{I} \neg$. However, this chapter is concerns standard propositional logic. So let us explore what is expressed by a system of classical propositional logic PL(without disjunction). Since PL- may be obtained by adding (DN) the law of double negation to $\mathrm{I} \neg$, the question of what PL- expresses amounts to finding what (DN) expresses.

$$
\text { (DN) } \frac{\mathrm{H} \vdash \sim \sim \mathrm{A}}{\mathrm{H} \vdash \mathrm{A}}
$$

It turns out that the corresponding condition expressed by (DN) is $\|\sim \sim\|$. (See Humberstone 1981 p. 318, who calls a related condition Refinability.)

$$
\|\sim \sim\| \text { If } \mathrm{v}(\mathrm{A})=\mathrm{f} \text { then for some } \mathrm{v}^{\prime}, \mathrm{v} \leq \mathrm{v}^{\prime} \text { and } \mathrm{v}^{\prime}(\mathrm{A})=\mathrm{F} \text {. }
$$

This condition can be read off from the validity of the classical argument $\sim \mathrm{A} \vdash \mathrm{A}$ using $\|\sim\|$. It amounts to saying that whenever a sentence is false at a valuation, there is always some extension of that valuation where it is settled false. Garson (1990, p. 163) shows that the system PL- expresses exactly the semantics $\|\mathrm{PL}-\|$, which is the conjunction of $\|\mathrm{I} \neg\|$ with $\|\sim \sim\|$.

Since we are thinking of $\|\mathrm{PL}-\|$ as an open future semantics, it is worth looking at what $\|\sim \sim\|$ says more carefully. Consider the sentence $\mathrm{A} \rightarrow \mathrm{A}$, where A reports some future event over which someone has control. So, for example, A might report a sea battle at a date in the future. Presumably A is unsettled, and so at the present situation $\mathrm{v}, \mathrm{v}(\mathrm{A})=\mathrm{v}(\sim \mathrm{A})=\mathrm{f}$. Though one can control $\mathrm{A}$, it does not seem correct to assert that one has control over $\mathrm{A} \rightarrow \mathrm{A}$. The reason is that $\mathrm{A} \rightarrow \mathrm{A}$ is inevitable, that is, it will turn out true no matter how A gets settled, and so my actions have nothing to do with settling it. Therefore, although $\mathrm{A}$ is unsettled, we want $\mathrm{A} \rightarrow \mathrm{A}$ to be settled true, since it is inevitable. This is exactly what $\|\sim \sim\|$ entails, for it amounts to the claim that all inevitable sentences are true, and hence settled true.

To demonstrate that, we will need an official definition of inevitability - the notion that a sentence is true at every point in the future where it is settled. Here it helps to deploy the concept of quasi-truth, for the inevitable sentences are simply those that are quasi-true at every possibility for the future. Humberstone (2011, p. 896) calls this weak inevitability.

(INV) $\mathrm{A}$ is inevitable at $\mathrm{v}$ iff for all $\mathrm{v}^{\prime} \in \mathrm{V}$, if $\mathrm{v} \leq \mathrm{v}^{\prime}$, then $\mathrm{v}^{\prime}(\mathrm{A})=\mathrm{qT}$.

It is now easy to prove that $\|\sim \sim\|$ is equivalent to || $\mathrm{IT} \|$, the claim that all inevitable sentences are settled true. 
|IT $\|$ If $\mathrm{A}$ is inevitable at $\mathrm{v}$, then $\mathrm{v}(\mathrm{A})=\mathrm{T}$.

Theorem: V obeys $\|\sim \sim\|$ iff V obeys \|IT||.

Proof. The contrapositive of $\|\sim \sim\|$ amounts to $\|\mathrm{C} \sim \sim\|$, and when the definition of inevitability is unpacked in $\|\mathrm{ITT}\|$, we have $\left\|\mathrm{IT}^{\prime}\right\|$.

$\|\mathrm{C} \sim \sim\|$ If for all $\mathrm{v}^{\prime} \in \mathrm{V}$, if $\mathrm{v} \leq \mathrm{v}^{\prime}$ then $\mathrm{v}^{\prime}(\mathrm{A}) \neq \mathrm{F}$, then $\mathrm{v}(\mathrm{A})=\mathrm{t}$.

$\left\|\mathrm{IT}^{\prime}\right\|$ If for all $\mathrm{v}^{\prime} \in \mathrm{V}$, if $\mathrm{v} \leq \mathrm{v}^{\prime}$, then $\mathrm{v}(\mathrm{A})=\mathrm{qT}$, then $\mathrm{v}(\mathrm{A})=\mathrm{T}$.

These are equivalent in light of (Fact 5) and (Fact 1).

The upshot of this theorem is that the semantic contribution of the law of double negation to the intuitionistic semantics amounts to exactly the requirement that inevitable sentences are settled true. This fits nicely with our intuitions about when agency is possible for situations described by sentences about the future.

\section{What Natural Deduction Rules for Disjunction Express}

It is natural to express our choices using disjunction. In this chapter, a discussion of disjunction has been postponed because of difficulties that arise for it in intuitionist logic. Taken alone, the system Sv consisting of ( $v$ In) and ( $v$ Out) expresses a condition || $\mathrm{Sv} \|$ on models that does not appear to provide properly recursive and noncircular truth conditions for the connective v. Although some possible solutions for the problem are suggested (Garson 2001, p. 126-127 and Garson 2013, Chapter 7), these are not fully satisfactory, for they require relaxing the standards for when a set of rules expresses connective meaning, or the addition of additional ad hoc semantical structure. One symptom of the problem is that the Persistence Lemma no longer holds when $\|\mathrm{Sv}\|$ is added to $\|\mathrm{I} \neg\|$.

A main result of this chapter is to show how these problems are resolved in standard propositional logic, where the classical condition $\|\sim \sim\|$ is expressed. When $\|\sim \sim\|$ holds, the system Sv of disjunction rules expresses the following relatively straightforward truth condition, which we call the quasi-truth interpretation for disjunction.

$$
\|\mathrm{qv}\| \mathrm{v}(\mathrm{AvB})=\mathrm{t} \text { iff for all } \mathrm{v}^{\prime} \in \mathrm{V}, \text { if } \mathrm{v} \leq \mathrm{v}^{\prime} \text { then } \mathrm{v}^{\prime}(\mathrm{A})=\mathrm{qT} \text { or } \mathrm{v}^{\prime}(\mathrm{B})=\mathrm{qT} .
$$

So the truth condition for $v$ expressed by a classical logic states that AvB is true when one of its disjuncts is quasi-true in every possible future. Though developed independently, this treatment of disjunction has already been deployed by 
Humberstone (1981) for a possibilities logic where situations are treated as sets of worlds, or time intervals. It is a simple matter to show that the open futures semantics given here is isomorphic to the propositional fragment of Humberstone's semantics.

The quasi-truth interpretation $\|\mathrm{qv}\|$ for disjunction is more than a random artifact of a search for what propositional logic expresses. It is well suited for matching intuitions about sentences of the form of Excluded Middle such as $A v \sim A$, when $A$ reads: 'there is a sea battle tomorrow at $t^{\prime}$ and ' $t$ ' refers to a time in the future. The reason $\mathrm{Av} \sim \mathrm{A}$ is settled true, and so not a target for agency, is that in every possible future, either $\mathrm{A}$ is true if settled or $\sim \mathrm{A}$ is true if settled. That follows directly from the fact that being settled true, being settled false and being unsettled are exhaustive categories. So the truth condition $\|\mathrm{qv}\|$ explains nicely how it can be that $\mathrm{Av} \sim \mathrm{A}$ is settled true at a time when both of its disjuncts is unsettled. Therefore $\|$ qv $\|$ both accepts Excluded Middle and leaves room for unsettled sentences. To put it another way, the semantics obeys the dictum: "no choice before its time" (Belnap 2005, Sect.3.1), since disjuncts of Av $\sim \mathrm{A}$ may remain unsettled. However, disjunctions may be settled well before the time their disjuncts are settled.

It may appear to the reader that we could simplify $\|q v\|$ by saying that $v(A v B)=t$ iff either A or B is inevitable at v. However, $\|q v\|$ does not say that the truth of AvB entails that one of its disjuncts is inevitable. (Pay attention to the relative scopes of 'or' and of the universal quantifier on the right hand side of $\|q v\|$.) Were that to be true, $\|q v\|$ would collapse to the classical truth condition, since the inevitability of a disjunct is equivalent to its being $\mathrm{t}$, by $\|\mathrm{IT}\|$. It is crucial to the very nature of $\|q v\|$ that the condition expressed by Sv not be classical, for were that to be true, the acceptance of $\mathrm{Av} \sim \mathrm{A}$, would entail that either $\mathrm{v}(\mathrm{A})=\mathrm{T}$ or $\mathrm{v}(\mathrm{A})=\mathrm{F}$, leaving no room for unsettled sentences. This in turn would convert the truth conditions for each of the connectives into its classical counterpart.

We are ready to report on the main result. Let the language of PL include the connectives $\&, \rightarrow, \sim$, and $v$, and let PL be PL- plus Sv, the ND rules for disjunction. Let $\|\mathrm{PL}\|$ be the semantics for the language of PL that results from adding $\|\mathrm{qv}\|$ to $\|$ PL- $-\|$. Then PL expresses || PL $\|$, and so ||PL\| qualifies as a natural semantics for PL.

Theorem 1. PL expresses $\|\mathrm{PL}\|$.

The proof of this theorem is found in Appendix A. This result immediately entails the completeness of PL for \|PL\|. (See Garson (1990), p. 159.)

\section{No Past Branching}

The accessibility relation in an open future semantics is ordinarily taken to be reflexive, transitive and antisymmetric.

(Antisymmetric) For all $\mathrm{v}, \mathrm{v}^{\prime}$ in $\mathrm{V}$, if $\mathrm{v} \leq \mathrm{v}^{\prime}$ and $\mathrm{v}^{\prime} \leq \mathrm{v}$, then $\mathrm{v}=\mathrm{v}^{\prime}$. 
The relation $\leq$ of $\|\mathrm{PL}\|$ obeys these three properties. However, it is also presumed that the set of open possibilities has the structure of a forward facing tree, with branching towards the future, but none in the past. Belnap, Perloff and Xu (2001, p. 185ff) argue that no branching in the past is essential to our concept of agency. So if ||PL\| were to count as a full-blooded open futures semantics, we would expect it to satisfy the following condition, for all $\mathrm{v}, \mathrm{v}^{\prime}$ and $\mathrm{u}$ in $\mathrm{V}$.

(No Past Branching) If $\mathrm{v} \leq \mathrm{u}$ and $\mathrm{v}^{\prime} \leq \mathrm{u}$ then $\mathrm{v} \leq \mathrm{v}^{\prime}$ or $\mathrm{v}^{\prime} \leq \mathrm{v}$.

However there are models V that obey ||PL\| where (No Past Branching) fails. Nothing said so far rules out the possibility that two valuations $\mathrm{v}$ and $\mathrm{v}^{\prime}$ might extend to the same valuation $\mathrm{u}$ even though the two are not comparable, that is neither $\mathrm{v} \leq \mathrm{v}^{\prime}$ nor $v^{\prime} \leq \mathrm{v}$. So one might object that $\|\mathrm{PL}\|$ does not really qualify as a semantics of the open future, since it does not treat the past properly. However, the problem can be repaired by constructing a finer individuation of the set of possibilities. Instead of taking the "moments" in our model to be valuations, think of them instead as pairs $<\mathrm{c}, \mathrm{v}>$ where $\mathrm{c}$ is a past for $\mathrm{v}$, that is, a connected set of valuations $\mathrm{u}$ that are earlier than $\mathrm{v}$ in the ordering $\leq$. Given any set of valuations $\mathrm{V}$ obeying $\|\mathrm{PL}\|$, it is possible to construct a past model $\mathrm{P}=<\mathrm{W}, \subseteq$, $\mathrm{u}>$ for $\mathrm{V}$ by letting the members of $\mathrm{W}$ be pairs $<\mathrm{c}, \mathrm{v}>$ where $\mathrm{c}$ is a past for $\mathrm{v}$ in $\mathrm{V}$, rather than the valuations themselves. (We could also require a past $\mathrm{c}$ to be a past history for $\mathrm{v}$, where $\mathrm{c}$ must be a maximal connected set, but all that does is to complicate the result given below.) This idea matches the intuition that were there to be two moments where all the same sentences were true but with different pasts, we would count them non-identical. By defining the relation $\subseteq$ and the assignment function $\mathrm{u}$ for $\mathrm{P}$ in the appropriate way, it will be possible to show that a past model for $\mathrm{V}$ has a relation $\subseteq$ that obeys (No Past Branching), and $\mathrm{P}$ preserves the truth-values for valuations in $\mathrm{V}$, in a sense to be made clear below. Therefore, a set of valuations $\mathrm{V}$ has the resources to set up a truth preserving structure that qualifies as a full-fledged semantics for an open future.

Here are the relevant definitions, where it is presumed that $\leq$ is defined by $(\leq)$ above.

(Connected) Relation $\leq$ is connected for set $\mathrm{s}$ iff for every $\mathrm{v}$ and $\mathrm{v}^{\prime} \in \mathrm{s}, \mathrm{v} \leq \mathrm{v}^{\prime}$ or $\mathrm{v}^{\prime} \leq \mathrm{v}$.

(Chain) A chain $\mathrm{c}$ (for $\mathrm{V}$ ) is a subset of $\mathrm{V}$ such that $\leq$ is connected for $\mathrm{c}$.

(Past for $\mathrm{v}$ ) $\mathrm{c}$ is a past for $\mathrm{v}$ iff $\mathrm{c}$ is a chain for $\mathrm{V}, \mathrm{v} \in \mathrm{c}$ and for every $\mathrm{u} \in \mathrm{c}, \mathrm{u} \leq \mathrm{v}$.

(Past Model for $\mathrm{V}$ ) The past model $\mathrm{P}=<\mathrm{W}, \subseteq, \mathrm{u}>$ for $\mathrm{V}$ is defined as follows:

$$
\mathrm{W}=\{<\mathrm{c}, \mathrm{v}>: \mathrm{c} \text { is a past for } \mathrm{v} \text { and } \mathrm{v} \in \mathrm{V}\} \text {. }
$$

To save eyestrain, we abbreviate pairs ' $<\mathrm{c}, \mathrm{v}>$ ' to ' $\mathrm{cv}$ '.

The relation $\subseteq$ is defined for $\mathrm{cv}$ and $\mathrm{c}^{\prime} \mathrm{v}^{\prime} \in \mathrm{W}$, as follows.

$$
(\subseteq) \mathrm{cv} \subseteq \mathrm{c}^{\prime} \mathrm{v}^{\prime} \text { iff } \mathrm{v} \leq \mathrm{v}^{\prime} \text { and } \mathrm{c}=\left\{\mathrm{u}: \mathrm{u} \in \mathrm{c}^{\prime} \text { and } \mathrm{u} \leq \mathrm{v}\right\}
$$


So $\mathrm{cv} \subseteq \mathrm{c}^{\prime} \mathrm{v}^{\prime}$ holds when $\mathrm{v}<\mathrm{v}^{\prime}$ and $\mathrm{c}$ and $\mathrm{c}^{\prime}$ agree on the past up to $\mathrm{v}$.

The assignment function $\mathrm{u}$ is defined for $\mathrm{cv} \in \mathrm{W}$, so that

$$
\mathrm{u}(\mathrm{cv}, \mathrm{p})=\mathrm{v}(\mathrm{p}) \text {, for propositional variables } \mathrm{p} \text {. }
$$

The function $\mathrm{u}$ is extended to the complex sentences by the following analogs of truth conditions in $\|\mathrm{PL}\|$, for arbitrary $\mathrm{w}$ in $\mathrm{W}$.

$$
\begin{aligned}
& \|\mathrm{u} \&\| \mathrm{u}(\mathrm{w}, \mathrm{A} \& \mathrm{~B})=\mathrm{t} \text { iff } \mathrm{u}(\mathrm{w}, \mathrm{A})=\mathrm{t} \text { and } \mathrm{u}(\mathrm{w}, \mathrm{B})=\mathrm{t} \text {. } \\
& \|\mathrm{u} \rightarrow\| \mathrm{u}(\mathrm{w}, \mathrm{A} \rightarrow \mathrm{B})=\mathrm{t} \text { iff for all } \mathrm{w}^{\prime} \in \mathrm{W} \text {, if } \mathrm{w} \subseteq \mathrm{w}^{\prime} \text {, then } \mathrm{u}\left(\mathrm{w}^{\prime}, \mathrm{A}\right)=\mathrm{f} \text { or } \mathrm{u}\left(\mathrm{w}^{\prime}, \mathrm{B}\right)=\mathrm{t} \\
& \|\mathrm{u} \sim\| \mathrm{u}(\mathrm{w}, \sim \mathrm{A})=\mathrm{t} \text { iff for all } \mathrm{w}^{\prime} \in \mathrm{W}, \text { if } \mathrm{w} \subseteq \mathrm{w}^{\prime}, \text { then } \mathrm{u}\left(\mathrm{w}^{\prime}, \sim \mathrm{A}\right)=\mathrm{f} \text {. } \\
& \|\mathrm{uqv}\| \mathrm{u}(\mathrm{w}, \mathrm{AvB})=\mathrm{t} \text { iff for all } \mathrm{w}^{\prime} \in \mathrm{W} \text {, if } \mathrm{w} \subseteq \mathrm{w}^{\prime} \text {, then for some } \mathrm{w}^{\prime \prime} \in \mathrm{W}, \mathrm{w}^{\prime} \subseteq \mathrm{w}^{\prime \prime} \text { and } \\
& \text { either } \mathrm{u}\left(\mathrm{w}^{\prime \prime}, \mathrm{A}\right)=\mathrm{t} \text { or } \mathrm{u}\left(\mathrm{w}^{\prime \prime}, \mathrm{B}\right)=\mathrm{t} \text {. }
\end{aligned}
$$

Now that the past model for $\mathrm{V}$ is defined, it is possible to show that Reflexivity, Transitivity, Antisymmetry and (No Past Branching) all hold in this model. So, in that sense, $\mathrm{V}$ generates a full-fledged open future semantics. We can also show that the past model for $\mathrm{V}$ is truth preserving in the sense that $\mathrm{u}(\mathrm{cv}, \mathrm{A})=\mathrm{v}(\mathrm{A})$ for all wffs $\mathrm{A}$ and any past $\mathrm{c}$ for $\mathrm{v}$. The intuition behind this result is that the truth conditions "face the future" and so are insensitive to adjustments to past structure created by past models.

Past Model Theorem. Let $\mathrm{V}$ be any set of valuations that obeys $\|\mathrm{PL}\|$. Then the past model $\mathrm{P}=<\mathrm{W}, \subseteq, \mathrm{u}>$ for $\mathrm{V}$ is such that $\mathrm{u}(\mathrm{cv}, \mathrm{A})=\mathrm{v}(\mathrm{A})$ for all wffs $\mathrm{A}$, and any past $\mathrm{c}$ for $\mathrm{v}$, and the frame $<\mathrm{W}, \subseteq>$ is reflexive, transitive, antisymmetric, and obeys (No Past Branching).

The proof of this theorem appears in Appendix B. The ability of $\mathrm{V}$ to generate past models is important because it shows that $\mathrm{V}$ has the resources for defining a frame $<\mathrm{W}, \subseteq>$ with the right structure for an open future. Furthermore, when any set of sentences $\mathrm{H}$ is satisfied by $\mathrm{V}$, we know that it is also satisfied in the past model for $\mathrm{V}$. As a result, any argument $\mathrm{H} / \mathrm{C}$ is $\mathrm{V}$-valid for all $\mathrm{V}$ obeying $\|\mathrm{PL}\|$ iff it is valid for all past models for $\mathrm{V}$.

\section{Open Future Semantics and Supervaluations}

The reader may complain that open futures semantics for PL is nothing new. The existence of non-classical interpretations for classical propositional logic has been well-known since the invention of supervaluation semantics (van Fraassen 1969). Supervaluations may be used to show how a sentence of the form Av $\sim$ A can be validated in three-valued scheme that allows the values of $\mathrm{A}$ and $\sim \mathrm{A}$ to be unsettled. So, supervaluations can already serve the role of providing for a logic of an open future.

Although it is granted that $\|\mathrm{PL}\|$ and supervaluations have some strong points of similarity, there are crucial points of difference, and these argue for the superiority 
of the open futures approach embodied in $\|\mathrm{PL}\|$. To make the issues clear, a brief account of supervaluation semantics is in order,

The fundamental idea behind supervaluations is to allow some sentences to remain undetermined, but only provided that would be compatible with truth-values fixed by classical truth tables. When the atomic constituents of a sentence A are not defined, the value of $\mathrm{A}$ is $\mathrm{t}$ if all ways of filling in the missing values using classical truth tables would assign $\mathrm{A} t$, and the value of $\mathrm{A}$ is $\mathrm{f}$ if every way of filling the missing values yields $\mathrm{f}$. Otherwise $\mathrm{A}$ is left undefined.

Let us present the idea more formally following (McCawley 1993, 334ff.). Let H be any consistent set of sentences. Let $\mathrm{H}=\mathrm{c}$ A mean that every classical valuation that satisfies $\mathrm{H}$ (assigns $\mathrm{t}$ to every member of $\mathrm{H}$ ) also satisfies $\mathrm{A}$ (assigns t to A). Then the supervaluation $s_{H}$ induced by set $H$ is the assignment of truth-values $\mathrm{T}, \mathrm{F}$, and $U$ (neither or undefined) such that (SVT), (SVF) and (SVU). hold.

$$
\begin{aligned}
& (\mathrm{SVT}) \mathrm{s}_{\mathrm{H}}(\mathrm{A})=\mathrm{T} \text { if } \mathrm{H} \models \mathrm{c} \mathrm{A} . \\
& (\mathrm{SVF}) \mathrm{s}_{\mathrm{H}}(\mathrm{A})=\mathrm{F} \text { if } \mathrm{H}=\mathrm{c} \sim \mathrm{A} . \\
& (\mathrm{SVU}) \mathrm{s}_{\mathrm{H}}(\mathrm{A})=\mathrm{U} \text { if neither } \mathrm{s}_{\mathrm{H}}(\mathrm{A})=\mathrm{T} \text { nor } \mathrm{s}_{\mathrm{H}}(\mathrm{A})=\mathrm{F} .
\end{aligned}
$$

The relation $\models \mathrm{s}$ of supervaluation validity is now defined as follows. $\mathrm{H} \models \mathrm{s} C$ holds iff every supervaluation induced by a consistent set of sentences that satisfies $\mathrm{H}$ also satisfies $\mathrm{C}$. A well-known result concerning supervaluations is that the notion of validity defined by the class of supervaluations is equivalent to classical validity, and so PL is sound and complete for supervaluation semantics.

Similarities between supervaluations and $\|\mathrm{PL}\|$ are obvious. Think of an inducing set $\mathrm{H}$ as defining a corresponding valuation $\mathrm{v}_{\mathrm{H}}$ such that $\mathrm{v}_{\mathrm{H}}(\mathrm{A})=\mathrm{t}$ exactly when $\mathrm{H}$ $\models c$ A. Now note the parallels between the conditions (SVT), (SVF), (SVU) and their counterparts (DefT), (DefF), (DefU) in $\|\mathrm{PL}\|$, which we write in equivalent forms with the help of (Fact 1) and (Fact 2) to emphasize the correspondence.

$$
\begin{aligned}
& (\text { DefT) } \mathrm{v}(\mathrm{A})=\mathrm{T} \text { iff } \mathrm{v}(\mathrm{A})=\mathrm{t} .(\text { Fact } 1) \\
& (\text { DefF }) \mathrm{v}(\mathrm{A})=\mathrm{F} \text { iff } \mathrm{v}(\sim \mathrm{A})=\mathrm{t} . \text { (Fact } 2) \\
& (\text { DefU }) \mathrm{v}(\mathrm{A})=\mathrm{U} \text { iff neither } \mathrm{v}(\mathrm{A})=\mathrm{T} \text { nor } \mathrm{v}(\mathrm{A})=\mathrm{F}
\end{aligned}
$$

This idea provides the basis for a result showing a 3-valued preserving isomorphism between the set of all supervaluations and the canonical model $\mathrm{V}_{\mathrm{PL}}$ of PL, which is defined as the set of all valuations $\mathrm{v}$ which are closed under deduction in PL, that is, such that whenever $\mathrm{v}(\mathrm{H})=\mathrm{t}$ and $\mathrm{H} \vdash \mathrm{C}, \mathrm{v}(\mathrm{C})=\mathrm{t}$. (See (Garson 2013, Section 9.2) for details.) This means we can translate from talk of valuations in $\mathrm{V}_{\mathrm{PL}}$ to talk of supervaluations at will.

A related point of similarity has to do with the partial truth tables for the connectives in the two schemes. A partial truth table records the 3-valued output ( $\mathrm{T}, \mathrm{F}$, or $\mathrm{U}$ ) for a connective as a function of its 3 -vauled inputs in a 3 by 3 matrix. The tables for the binary connectives are not entirely functional (hence the term 'partial'), since it is only possible to fix 8 of the 9 values uniquely, leaving one cell where 
two values are possible. Garson (2013, Section 9.3) shows that the partial tables for supervaluations and those for sets of valuations that satisfy $\|\mathrm{PL}\|$ are identical.

Despite these similarities, there are fundamental and crucial differences between $\|P L\|$ and supervaluation semantics. Not only is supervaluation semantics not a legitimate interpretation for PL, it fails to define any meanings for the connectives at all.

One point should be clear at the outset. $\|\mathrm{PL}\|$ provides an alternative semantics for PL by providing intensional truth conditions for the connectives with the help of a structure $<\mathrm{V}, \leq>$ that can be read as defining a temporal/modal order. Supervaluations simply lack this structure, so they do not qualify as semantics for an open future. Furthermore, it is far from clear that supervaluation semantics offers any particular account of connective truth conditions. Granted, a statement of connective truth conditions is implicit in the consequence relation $=\mathrm{c}$ where classical conditions are chosen. However, it would not change the outcome in any way were we to define $\models \mathrm{c}$ using || $\mathrm{PL} \|$ or even proof theoretically, so that $\mathrm{H} \models \mathrm{c} \mathrm{C}$ iff $\mathrm{H} \vdash_{\mathrm{PL}} \mathrm{C}$. All that matters for success of the supervaluation tactic is that the relation $\models$ c pick out the valid arguments of propositional logic, and this can be done with an alternative semantics or even using syntactic means. Therefore, supervaluation semantics radically underdetermines the meaning of the connectives, if it gives them any meanings at all.

A second major point of difference is that supervaluations do not preserve the validity of the PL rules. Supervaluation semantics is not sound for PL, so it can hardly count as a way of interpreting its rules. Early on (van Fraassen (1969, p. 81) noted that the following classical rule is unsound for some classes of supervaluations that are subsets of SV.

$$
\frac{\mathrm{A} \vdash \mathrm{B}}{\sim \mathrm{B} \vdash \sim \mathrm{A}}
$$

This failure is pervasive. All classical ND rules that discharge hypotheses fail as well: for example $(\rightarrow$ In), $(\sim$ In $),(\sim$ Out $)$ and (v Out). Williamson $(1984$, p. 120) takes this to be a profound betrayal of our ordinary deductive practices, and argues that therefore supervaluations are not up to the task of providing a coherent account of vagueness. Analog complaints against treating supervaluation semantics as an account of the open future seem equally compelling.

The upshot of this is that the pathological behavior of supervaluations is massive. While supervaluation semantics accepts as valid the valid arguments of PL, that is, the arguments PL asserts, it does not respect the deductive behavior of $\rightarrow, \sim$, and $\mathrm{V}$ as embodied in their natural deduction rules. So, it disagrees fundamentally with the use to which the connectives are put.

This underscores an important moral. A theory that attempts to define connective meaning by which arguments are accepted, faces problems of underdetermination. As Garson (2013) shows, traditional systems built from axioms and rules defined over sentences faces massive underdetermination results. They simply cannot define any coherent meanings for the connectives. Supervaluations fail to give meanings to the 
connectives for a similar reason: they simply fail to do justice to the uses to which the connectives are put in the process of reasoning from one argument form to another. On the other hand, a theory that takes seriously the deductive roles connectives play, by exploring constraints that arise from assuming that the rules preserve validity, may fix a unique interpretation of the connectives, as does $\|$ PL $\|$. For those who adopt the natural deduction rules of PL to guide their reasoning, ||PL $\|$ tells us what the connectives mean. It should come as no surprise that $\|\mathrm{PL}\|$ is useful, since it is the interpretation most of us have been employing all along whether we know it or not.

\section{Defeating Fatalism}

The reader may have serious worries about $\|$ PL $\|$. (Fact 1) entails that truth and settled truth are the same thing.

(Fact 1) If $\mathrm{v}(\mathrm{A})=\mathrm{t}$ then $\mathrm{v}(\mathrm{A})=\mathrm{T}$.

Furthermore, since PL is classical, the Law of Excluded Middle is a theorem. The concern is that these two features do not leave room for unsettled values in the semantics. Arguments related to this concern have surfaced at many points in the literature. Two notable examples are Taylor (1962) famous argument for fatalism, and Williamson's purported demonstration that supervaluation semantics has no room for unsettled values (1994, p. 300).

Here a basic argument form concerning $\mid$ PL $\|$ will be examined with an eye to uncovering the flaw in its reasoning. Once the main idea is in place, the same solution may be applied wherever arguments of this kind arise. Here is the basic argument form:

\section{Ur Argument for Fatalism}

A or not-A.
If A, then it is settled that A.
If not-A, then it is settled that not-A. (Fact 1)
Therefore, either it is settled that A or settled that not-A.

The argument has the form of (v Out), so it is classically valid. The premises appear indisputable, since adopting classical logic gives us Excluded Middle and (Fact 1) was proven for $\|\mathrm{PL}\|$. It appears to follow that there is no room in $\|\mathrm{PL}\|$ for any unsettled sentences, for when it is settled that not-A, that is, $\mathrm{v}(\sim \mathrm{A})=\mathrm{T}$, we have $\mathrm{v}(\mathrm{A})=\mathrm{F}$, so that the conclusion of the argument asserts that A must be settled true or settled false, hence settled.

The problem with this reasoning is that it does not take proper care in distinguishing the object language from the metalanguage. Therefore, the English renderings 
of the premises of the Ur Argument are ambiguous. Let us attempt to rewrite the argument more accurately using the notation: ' $\mathrm{v}(\mathrm{A})=$ ' in which (Fact 1 ) is actually written. Here we assume $\mathrm{v}$ is an arbitrary member of $\mathrm{V}$.

\section{v Argument for Fatalism}

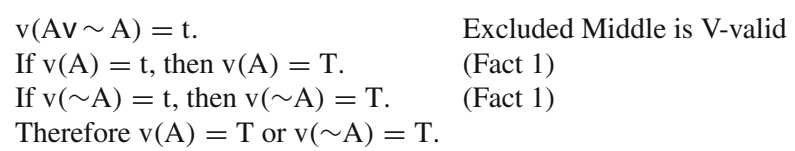

It should clear right away that this argument is invalid. The problem is that we need:

$$
(\text { or } \sim) \mathrm{v}(\mathrm{A})=\mathrm{t} \text { or } \mathrm{v}(\sim \mathrm{A})=\mathrm{t} .
$$

rather than what we see in the first premise: $\mathrm{v}(\mathrm{A} v \sim \mathrm{A})=\mathrm{t}$ in order for it to have the form of (v Out) in the metalanguage. So let us replace the first premise with (or $\sim)$.

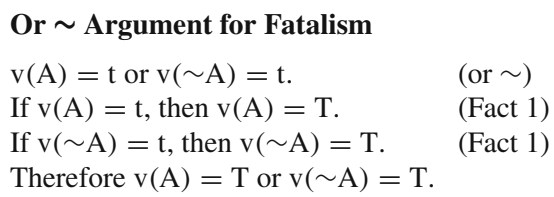

This will not help matters, since here is no reason to accept (or $\sim$ ). As (or $\sim$ ) does not have the form of Excluded Middle, there is no classical argument in its favor. Furthermore, it begs the question, because (or $\sim$ ) just amounts to the claim that there are no unsettled values. Even worse, (or $\sim)$ is demonstrably false. We can find models V that obey $\|$ PL $\|$ where there are unsettled values. For example, consider the set $\mathrm{V}^{*}$ of valuations $\mathrm{v}$ that respect deductive closure in $\mathrm{PL}$, that is, if $\mathrm{v}(\mathrm{H})=\mathrm{t}$ and $\mathrm{H} \vdash_{\mathrm{PL}} \mathrm{C}$ then $\mathrm{v}(\mathrm{C})=\mathrm{t}$. It is near trivial to prove that $\mathrm{V}^{*}$ is a model of PL, and since $\|\mathrm{PL}\|$ is expressed by PL, $\mathrm{V}^{*}$ must obey PL. However, there are many members of $\mathrm{V}^{*}$, notably the valuation $\mathrm{v} \vdash$ that assigns $t$ to all and only theorems of $\mathrm{PL}$ which allow $\mathrm{v} \vdash(\mathrm{p})=\mathrm{v} \vdash(\sim \mathrm{p})=\mathrm{f}$.

Perhaps a second variation of this argument form might work by changing the first premise to a claim with the form of Excluded Middle that is true of $\|\mathrm{PL}\|$, where the disjunction and negation are expressed in the metalanguage, and the third premise is modified to guarantee that the argument has the form of (vOut): 


\section{Or Not Argument for Fatalism}

$$
\begin{array}{ll}
\mathrm{v}(\mathrm{A})=\mathrm{t} \text { or not } \mathrm{v}(\mathrm{A})=\mathrm{t} . & \text { Metalanguage Excluded Middle } \\
\text { If } \mathrm{v}(\mathrm{A})=\mathrm{t}, \text { then } \mathrm{v}(\mathrm{A})=\mathrm{T} . & \text { (Fact } 1) \\
\text { If not } \mathrm{v}(\mathrm{A})=\mathrm{t}, \text { then } \mathrm{v}(\sim \mathrm{A})=\mathrm{T} . & ? ? ? ? ? \\
\text { Therefore } \mathrm{v}(\mathrm{A})=\mathrm{T} \text { or } \mathrm{v}(\sim \mathrm{A})=\mathrm{T} . &
\end{array}
$$

However, the third premise is no longer supported by (Fact 1), and it is demonstrable that this claim is false for some valuations in models that obey $\|\mathrm{PL}\|$. If not $\mathrm{v}(\mathrm{A})=\mathrm{t}$, then $\mathrm{v}(\mathrm{A})=\mathrm{f}$. But this, as we have just argued, is compatible with $\mathrm{v}(\sim \mathrm{A})=\mathrm{f}$, thus undermining $\mathrm{v}(\sim \mathrm{A})=\mathrm{T}$. (See Brown ann Garson (in preparation) for the deployment of this tactic to show that ||PL || can overcome problems Williamson lodges against supervaluations.)

The upshot of this is that (Fact 1), acceptance of Excluded Middle, and the existence of unsettled sentences are demonstrably compatible with each other. In fact $\|\mathrm{PL}\|$, the very semantics that tells us what is expressed by classical rules, shows how this is possible. The secret is that the quasi-truth interpretation of disjunction makes room for accepting $\mathrm{A} v \sim \mathrm{A}$ when the value of $\mathrm{A}$ is unsettled.

This realization has direct applications to a variety of arguments that purport to show that there cannot be an open future. Take a simplification of Taylor's famous argument (Taylor 1962, p. 129 ff.) for fatalism. Here Q abbreviates "A naval battle will occur", and $\mathrm{O}$ abbreviates "I issue the order for the battle", and it is presumed that $\mathrm{O}$ is necessary and sufficient for $\mathrm{Q}$.

$\mathrm{Q}$ is true or not-Q is true.

If $\mathrm{Q}$, then $\mathrm{O}$ is out of my control.

If not-Q, then not-O is out of my control.

Therefore, $\mathrm{O}$ is out of my control or not-O is out of my control.

Given the strategy of $\|\mathrm{PL}\|$ semantics, it may appear that the argument has a valid form, and that all premises must be accepted. ||PL $\mid$ would apparently support the second premise, because if $\mathrm{Q}$ is true, $\mathrm{Q}$ is settled true, and whatever is settled true entails the settled truth of any sentence (such as $\mathrm{O}$ ) necessary for $\mathrm{Q}$. Therefore $\mathrm{O}$ is settled and therefore not the subject of my control despite its being in the future. Similar reasoning can be given to support the third premise. It appears ||PL\| yields fatalist conclusions.

However, it is easy to see what has gone wrong when care is taken to present the argument with sufficient notational detail. If we take its form to be the analog of the v Fatalist argument, we have the following, which has a true first premise and an invalid form:

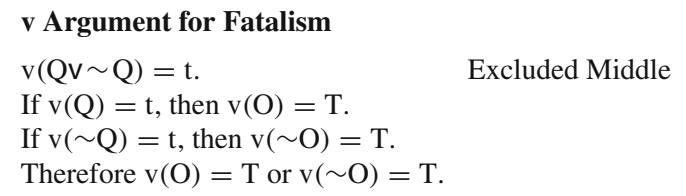


Modifying the first premise yields a valid form:

\section{Or Argument for Fatalism}

$$
\begin{aligned}
& \mathrm{v}(\mathrm{Q})=\mathrm{t} \text { or } \mathrm{v}(\sim \mathrm{Q})=\mathrm{t} . \\
& \text { If } \mathrm{v}(\mathrm{Q})=\mathrm{t} \text {, then } \mathrm{v}(\mathrm{O})=\mathrm{T} . \\
& \text { If } \mathrm{v}(\sim \mathrm{Q})=\mathrm{t} \text {, then } \mathrm{v}(\sim \mathrm{O})=\mathrm{T} \text {. } \\
& \text { Therefore } \mathrm{v}(\mathrm{O})=\mathrm{T} \text { or } \mathrm{v}(\sim \mathrm{O})=\mathrm{T} .
\end{aligned}
$$

However, the first premise no longer has the form of Excluded Middle, and in fact begs the question by claiming that $\mathrm{Q}$ is determined, something that can be refuted in $\|\mathrm{PL}\|$.

Suppose we attempt to fix this by expressing the negation in the object language and modifying the third premise to maintain the form of ( $v$ Out).

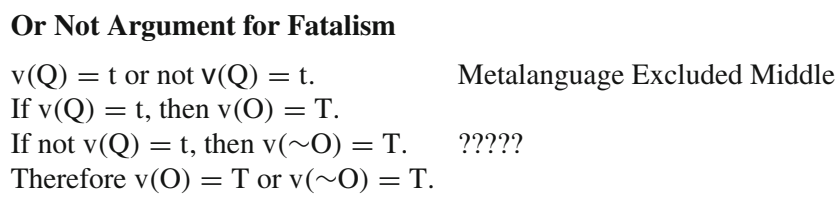

Now the third premise is the problem, for it is demonstrably false.

When $v(Q)$ is not t, it is f. Since Q is necessary and sufficient for $O, O$ is also $\mathrm{f}$, and its being $\mathrm{f}$ is compatible with $\mathrm{O}$ 's being unsettled, and hence a target for agency.

The conclusion to be drawn is that because classical logic essentially takes on an open futures interpretation, it automatically has the resources to undermine arguments for fatalism, and this despite its acceptance of Excluded Middle and the seemingly fatalist proposal that truth amounts to settled truth.

Open Access This chapter is distributed under the terms of the Creative Commons Attribution Noncommercial License, which permits any noncommercial use, distribution, and reproduction in any medium, provided the original author(s) and source are credited.

\section{Appendix A}

Here we provide a proof of Theorem 1.

Theorem 1. PL expresses $\|\mathrm{PL}\|$.

The first task is to verify that the Persistence Lemma holds for $\|\mathrm{PL}\|$.

$\leq$ Lemma. If $\mathrm{V}$ obeys $\|\mathrm{PL}\|$, then $\mathrm{v} \leq \mathrm{v}^{\prime}$ iff for a every wff $\mathrm{A}$, if $\mathrm{v}(\mathrm{A})=\mathrm{t}$ then $\mathrm{v}^{\prime}(\mathrm{A})=\mathrm{T}$. 
Proof. Let us define: $v \leq{ }_{A} v^{\prime}$ to mean that for every wff $A$, if $v(A)=t$ then $v^{\prime}(A)=t$. Let $\mathrm{V}$ be any set of valuations such that $\|\mathrm{PL}\|$ holds. It will be sufficient to show that $\mathrm{v} \leq \mathrm{v}^{\prime}$ iff $\mathrm{v} \leq \mathrm{A}^{\prime}$. The proof from right to left is trivial. Now assume $\mathrm{v} \leq \mathrm{v}^{\prime}$, and show that for any wff $\mathrm{A}$, if $\mathrm{v}(\mathrm{A})=\mathrm{t}$ then $\mathrm{v}^{\prime}(\mathrm{A})=\mathrm{t}$ by mathematical induction on the length of $\mathrm{A}$. For the base case we must show that when $\mathrm{A}$ is a propositional variable $\mathrm{p}$, if $\mathrm{v}(\mathrm{A})=\mathrm{t}$ then $\mathrm{v}^{\prime}(\mathrm{A})=\mathrm{t}$. This is guaranteed by the definition of $\leq$. For the inductive case, assume the inductive hypothesis for wffs $\mathrm{B}$ and $\mathrm{C}$, and show that it holds when $\mathrm{A}$ has one of the forms $\mathrm{B} \& \mathrm{C}, \mathrm{B} \rightarrow \mathrm{C}, \sim \mathrm{B}$, and $\mathrm{BvC}$ as follows.

A has the form $\mathbf{B} \& \mathbf{C}$. Assume $\mathrm{v}(\mathrm{B} \& \mathrm{C})=\mathrm{t}$, from $\|\&\|$ it follows that $\mathrm{v}(\mathrm{B})=\mathrm{t}$ and $\mathrm{v}(\mathrm{C})=\mathrm{t}$. By the inductive hypothesis, $\mathrm{v}^{\prime}(\mathrm{B})=\mathrm{t}$ and $\mathrm{v}^{\prime}(\mathrm{C})=\mathrm{t}$, and so $\mathrm{v}^{\prime}(\mathrm{B} \& \mathrm{C})=\mathrm{t}$ by $\|\&\|$.

A has the form $\mathbf{B} \rightarrow \mathbf{C}$. Assume $\mathrm{v}(\mathrm{B} \rightarrow \mathrm{C})=\mathrm{t}$, and establish $\mathrm{v}^{\prime}(\mathrm{B} \rightarrow \mathrm{C})=\mathrm{t}$ using $\|\rightarrow\|$. Assume that $\mathrm{v}^{\prime \prime}$ is an arbitrary member of $\mathrm{V}$ such that $\mathrm{v}^{\prime} \leq \mathrm{v}^{\prime \prime}$ and show that $\mathrm{v}^{\prime \prime}(\mathrm{B})=$ for $\mathrm{v}^{\prime \prime}(\mathrm{C})=\mathrm{t}$ as follows. From $\mathrm{v} \leq \mathrm{v}^{\prime}, \mathrm{v}^{\prime} \leq \mathrm{v}^{\prime \prime}$ and the transitivity of $\leq$, it follows that $\mathrm{v} \leq \mathrm{v}^{\prime \prime}$. Given $\mathrm{v}(\mathrm{B} \rightarrow \mathrm{C})=\mathrm{t}$, it follows by $\|\rightarrow\|$ that either $\mathrm{v}^{\prime \prime}(\mathrm{B})=\mathrm{f}$ or $\mathrm{v}^{\prime \prime}(\mathrm{C})=\mathrm{t}$ as desired.

A has the form $\sim$ A. Proof similar to the preceding case.

A has the form BvC. Assume $\mathrm{v}(\mathrm{BvC})=\mathrm{t}$, and establish $\mathrm{v}^{\prime}(\mathrm{BvC})=\mathrm{t}$ as follows. By $\|q v\|$, it will be sufficient to show that for all $v^{\prime \prime}$ if $v^{\prime} \leq v^{\prime \prime}$, then $v^{\prime \prime}(B)=q T$ or $\mathrm{v}^{\prime \prime}(\mathrm{C})=\mathrm{qT}$. So assume that $\mathrm{v}^{\prime} \leq \mathrm{v}^{\prime \prime}$ for any valuation $\mathrm{v}^{\prime \prime}$. Then by transitivity of $\leq$, $\mathrm{v} \leq \mathrm{v}^{\prime \prime}$, and by $\|\mathrm{qv}\|$ and $\mathrm{v}(\mathrm{BvC})=\mathrm{t}$, it follows that $\mathrm{v}^{\prime \prime}(\mathrm{B})=\mathrm{qT}$ or $\mathrm{v}^{\prime \prime}(\mathrm{C})=\mathrm{qT}$ as desired.

Now for the main theorem.

\section{Theorem 1. PL expresses \|PL\|.}

Proof. To show PL expresses \|PL\|, it must be shown that V obeys \|PL\| iff the rules PL are V-valid. For the proof of this from left to right, assume V obeys ||PL\| and show that the rules preserve V-validity as follows. The demonstration for rules other than those for disjunction is found in (Garson 1990, Theorems 1-3 pp. $21 \mathrm{ff}$.). What remains to show is that ( $\mathrm{In}$ ) and ( $\mathrm{v}$ Out) preserve V-validity.

(vIn). Assume $\mathrm{H} \models_{\mathrm{V}} \mathrm{A}$ and show that $\mathrm{H} \models_{\mathrm{V}} A \mathrm{AvB}$ by assuming that $\mathrm{v}$ is any member of $\mathrm{V}$ such that $\mathrm{v}(\mathrm{H})=\mathrm{t}$ and proving that $\mathrm{v}(\mathrm{AvB})=\mathrm{t}$ as follows. In light of $\|\mathrm{qv}\|, \mathrm{v}(\mathrm{AvB})=\mathrm{t}$ will follow if we demonstrate that whenever $\mathrm{v} \leq \mathrm{v}^{\prime}, \mathrm{v}^{\prime}(\mathrm{A})=\mathrm{qT}$ or $\mathrm{v}^{\prime}(\mathrm{B})=\mathrm{qT}$. So let $\mathrm{v}^{\prime}$ be any member of $\mathrm{V}$ such that $\mathrm{v} \leq \mathrm{v}^{\prime}$. From $\mathrm{H} \models \mathrm{v}$ A and $\mathrm{v}(\mathrm{H})=\mathrm{t}$, it follows that $\mathrm{v}(\mathrm{A})=\mathrm{t}$. Hence by $\mathrm{v} \leq \mathrm{v}^{\prime}$ and the $\leq$ Lemma, $\mathrm{v}^{\prime}(\mathrm{A})=\mathrm{t}$. From this it follows immediately by $($ Fact 1$)$ that $\mathrm{v}^{\prime}(\mathrm{A})=\mathrm{T}$, and hence $\mathrm{v}^{\prime}(\mathrm{A})=\mathrm{qT}$. The proof that if $\mathrm{H}=_{\mathrm{V}} \mathrm{B}$ then $\mathrm{H} \models_{\mathrm{V}}$ AvB is similar.

(vOut). Assume (1) $\mathrm{H} \models_{\mathrm{V}} \mathrm{AvB}$ (2) $\mathrm{H}, \mathrm{A} \models_{\mathrm{V}} \mathrm{C}$ and (3) $\mathrm{H}, \mathrm{B} \models_{\mathrm{V}} \mathrm{C}$, and show that $\mathrm{H} \models_{\mathrm{V}} \mathrm{C}$, by assuming the opposite and deriving a contradiction. From $\mathrm{H} \nvdash_{\mathrm{V}}$ $\mathrm{C}$ it follows that for some $\mathrm{v}$ in $\mathrm{V}, \mathrm{v}(\mathrm{H})=\mathrm{t}$ and $\mathrm{v}(\mathrm{C})=\mathrm{f}$. Given (1) $\mathrm{H} \models \mathrm{v}$ AvB, it follows that $\mathrm{v}(\mathrm{AvB})=\mathrm{t}$. By $\|\sim \sim\|$ and $\mathrm{v}(\mathrm{C})=\mathrm{f}$, it follows that for some $\mathrm{v}^{\prime}$ such that $\mathrm{v} \leq \mathrm{v}^{\prime}, \mathrm{v}^{\prime}(\mathrm{C})=\mathrm{F}$. By $\|\mathrm{qv}\|, \mathrm{v}(\mathrm{AvB})=\mathrm{t}$, and $\mathrm{v} \leq \mathrm{v}^{\prime}$, it follows that $\mathrm{v}^{\prime}(\mathrm{A})=\mathrm{qT}$ or $\mathrm{v}^{\prime}(\mathrm{B})=\mathrm{qT}$. Suppose it is $\mathrm{v}^{\prime}(\mathrm{A})$ that is $\mathrm{qT}$. By (Fact 5), $\mathrm{v}^{\prime}(\mathrm{A}) \neq \mathrm{F}$, 
and so by (DefF), there must be some $\mathrm{v}^{\prime \prime} \in \mathrm{V}$ such that $\mathrm{v}^{\prime} \leq \mathrm{v}^{\prime \prime}$ and $\mathrm{v}^{\prime \prime}(\mathrm{A})=\mathrm{t}$. By $\mathrm{v}(\mathrm{H})=\mathrm{t}$, the transitivity of $\leq$, and the $\leq$ Lemma, we have that $\mathrm{v}^{\prime \prime}(\mathrm{H})=\mathrm{t}$. From $\mathrm{v}^{\prime \prime}(\mathrm{A})=\mathrm{t}$ and (2) $\mathrm{H}, \mathrm{A} \models_{\mathrm{v}} \mathrm{C}$, we have $\mathrm{v}^{\prime \prime}(\mathrm{C})=\mathrm{t}$. But $\mathrm{v}^{\prime} \leq \mathrm{v}^{\prime \prime}$ and $\mathrm{v}^{\prime}(\mathrm{C})=\mathrm{F}$ entails that $\mathrm{v}^{\prime \prime}(\mathrm{C})=\mathrm{f}$ a contradiction. Similarly a contradiction follows from (3) $\mathrm{H}$, $\mathrm{B} \models_{\mathrm{V}} \mathrm{C}$ assuming $\mathrm{v}^{\prime \prime}(\mathrm{B})=\mathrm{t}$. Either way, we have the desired contradiction.

The next stage of the proof is to show that when the rules of PL preserve V-validity, $\mathrm{V}$ obeys $\|\mathrm{PL}\|$. The proof that $\mathrm{V}$ obeys the truth conditions of $\|\mathrm{PL}-\|$ is given in Garson (1990 pp. 121ff.), and the demonstration for $\|\sim \sim\|$ is given in Garson (2001, Lemma 4.4 p. 164), so all that remains is to show that when both ( $\mathrm{V}$ In) and (v Out) preserve $\mathrm{V}$-validity, $\mathrm{V}$ obeys $\|\mathrm{qv}\|$ as follows.

Proof of $\|\mathrm{qv}\|$ from left to right. Assume that $\mathrm{v}(\mathrm{AvB})=\mathrm{t}$, and $\mathrm{v} \leq \mathrm{v}^{\prime}$ for an arbitrary member $\mathrm{v}^{\prime}$ of $\mathrm{V}$, and show that $\mathrm{v}^{\prime}(\mathrm{A})=\mathrm{qT}$ or $\mathrm{v}^{\prime}(\mathrm{B})=\mathrm{qT}$ as follows. Since $\mathrm{v}^{\prime}$ is a valuation, there is a sentence $C$ such that $\mathrm{v}^{\prime}(C)=f$. Let $\mathrm{H}_{\mathrm{v}^{\prime}}$ be the set of sentences assigned $t$ by $\mathrm{v}^{\prime}$. It follows that $\mathrm{H}_{\mathrm{v}^{\prime}} \models \mathrm{v} A \mathrm{AB}$ by the following reasoning. Let $\mathrm{u}$ be any member of $\mathrm{V}$ such that $\mathrm{u}\left(\mathrm{H}_{\mathrm{v}^{\prime}}\right)=\mathrm{t}$ and show $\mathrm{u}(\mathrm{AvB})=\mathrm{t}$ as follows. Since $\mathrm{u}\left(\mathrm{H}_{\mathrm{v}^{\prime}}\right)=\mathrm{t}$, it follows that $\mathrm{v}^{\prime} \leq \mathrm{u}$. But we had that $\mathrm{v}(\mathrm{AvB})=\mathrm{t}, \mathrm{v} \leq \mathrm{v}^{\prime}$, and $\mathrm{v}^{\prime} \leq \mathrm{u}$, so $\mathrm{u}(\mathrm{AvB})=\mathrm{t}$ by the $\leq$ Lemma and the transitivity of $\leq$. This establishes $\mathrm{H}_{\mathrm{v}^{\prime}}=\mathrm{v}$ AvB; but we also have $\mathrm{v}^{\prime}\left(\mathrm{H}_{\mathrm{v}^{\prime}}\right)=\mathrm{t}$ and $\mathrm{v}^{\prime}(\mathrm{C})=\mathrm{f}$, so $\mathrm{H}_{\mathrm{v}^{\prime}} \not \nvdash_{\mathrm{v}} \mathrm{C}$. It follows from the fact that (v Out) preserves $\mathrm{V}$-validity that either $\mathrm{H}_{\mathrm{v}^{\prime}}, \mathrm{A} \not \nvdash_{\mathrm{v}} \mathrm{C}$ or $\mathrm{H}_{\mathrm{v}^{\prime}}, \mathrm{B} \not \nvdash_{\mathrm{v}} \mathrm{C}$. In the first case, there must be a valuation $\mathrm{v}^{\prime \prime}$ such that $\mathrm{v}^{\prime \prime}\left(\mathrm{H}_{\mathrm{v}}, \mathrm{A}\right)=\mathrm{t}$ and $\mathrm{v}^{\prime \prime}(\mathrm{C})=\mathrm{f}$. Because $\mathrm{v}^{\prime \prime}\left(\mathrm{H}_{\mathrm{v}^{\prime}}\right)=\mathrm{t}, \mathrm{v}^{\prime} \leq \mathrm{v}^{\prime \prime}$. Since $\mathrm{v}^{\prime \prime}(\mathrm{A})=\mathrm{t}$, and $\mathrm{v}^{\prime} \leq \mathrm{v}^{\prime \prime}, \mathrm{v}^{\prime}(\mathrm{A}) \neq \mathrm{F}$, hence by $($ Fact 5$), \mathrm{v}^{\prime}(\mathrm{A})=\mathrm{qT}$. Therefore $\mathrm{v}^{\prime}(\mathrm{A})=\mathrm{qT}$ or $\mathrm{v}^{\prime}(\mathrm{B})=\mathrm{qT}$ as desired. The second case, where $\mathrm{H}_{\mathrm{v}^{\prime}}, \mathrm{B} \not \nvdash_{\mathrm{v}} \mathrm{C}$, is similar.

Proof of $\|\mathrm{qv}\|$ from right to left. Assume that for all $\mathrm{v}^{\prime} \in \mathrm{V}$, if $\mathrm{v} \leq \mathrm{v}^{\prime}$, then $\mathrm{v}^{\prime}(\mathrm{A})=\mathrm{qT}$ or $\mathrm{v}^{\prime}(\mathrm{B})=\mathrm{qT}$, and show that $\mathrm{v}(\mathrm{AvB})=\mathrm{t}$ as follows. By the contrapositive $\|\mathrm{C} \sim \sim\|$ of $\|\sim \sim\|$, it will be sufficient for proving $\mathrm{v}(\mathrm{AvB})=\mathrm{t}$ to show that for any $\mathrm{v}^{\prime} \in \mathrm{V}$ if $\mathrm{v} \leq \mathrm{v}^{\prime}$, then $\mathrm{v}^{\prime}(\mathrm{AvB}) \neq \mathrm{F}$.

$\|\mathrm{C} \sim \sim\|$ If for all $\mathrm{v}^{\prime} \in \mathrm{V}$, if $\mathrm{v} \leq \mathrm{v}^{\prime}$ then $\mathrm{v}^{\prime}(\mathrm{A}) \neq \mathrm{F}$, then $\mathrm{v}(\mathrm{A})=\mathrm{t}$.

So let $\mathrm{v}^{\prime}$ be any member of $\mathrm{V}$ such that $\mathrm{v} \leq \mathrm{v}^{\prime}$ and show $\mathrm{v}^{\prime}(\mathrm{AvB}) \neq \mathrm{F}$ as follows. By our initial assumption, we have $\mathrm{v}^{\prime}(\mathrm{A})=\mathrm{qT}$ or $\mathrm{v}^{\prime}(\mathrm{B})=\mathrm{qT}$. Suppose that $\mathrm{v}^{\prime}(\mathrm{A})=\mathrm{qT}$. Then by $($ Fact 5$), v^{\prime}(A) \neq F$ and for some $v^{\prime \prime}, v^{\prime} \leq v^{\prime \prime}$ and $v^{\prime \prime}(A)=t$. Since the $\mathrm{V}$-validity of the rules of PL is preserved, all provable arguments of PL are V-valid including $\mathrm{A} \vdash \mathrm{AvB}$ and $\mathrm{B} \vdash \mathrm{AvB}$. Therefore for any valuation $\mathrm{v} \in \mathrm{V}$, if either $\mathrm{v}(\mathrm{A})=\mathrm{t}$ or $\mathrm{v}(\mathrm{B})=\mathrm{t}, \mathrm{v}(\mathrm{AvB})=\mathrm{t}$. By $\mathrm{v}^{\prime \prime}(\mathrm{A})=\mathrm{t}$, it follows that $\mathrm{v}^{\prime \prime}(\mathrm{AvB})=\mathrm{t}$ and so $\mathrm{v}^{\prime}(\mathrm{AvB}) \neq \mathrm{F}$ as desired. When $\mathrm{v}^{\prime}(\mathrm{B})=\mathrm{qT}$, the reasoning is similar.

This completes the proof of the theorem.

\section{Appendix B}

Here we prove the Past Model Theorem. 
Past Model Theorem. Let $\mathrm{V}$ be any set of valuations that obeys $\|\mathrm{PL}\|$. Then the past model $\mathrm{P}=\langle\mathrm{W}, \subseteq, \mathrm{u}>$ for $\mathrm{V}$ is such that $\mathrm{u}(\mathrm{cv}, \mathrm{A})=\mathrm{v}(\mathrm{A})$ for all wffs $\mathrm{A}$, and any past $\mathrm{c}$ for $\mathrm{v}$, and the frame $<\mathrm{W}, \subseteq>$ is reflexive, transitive, antisymmetric and obeys (No Past Branching).

We begin with a few lemmas.

Lemma 1. If $<\mathrm{W}, \subseteq, \mathrm{u}>$ is a past model for $\mathrm{V}$, then $<\mathrm{W}, \subseteq>$ is reflexive, transitive, antisymmetric and obeys (No Past Branching).

Proof. It is easy to verify that $\langle\mathrm{W}, \subseteq>$ is reflexive, transitive and antisymmetric. To show that it obeys (No Past Branching), let $c v, c^{\prime} v^{\prime}$, and $c^{\prime \prime} v^{\prime \prime}$ be any members of $\mathrm{W}$, such that $\mathrm{c}^{\prime} \mathrm{v}^{\prime} \subseteq \mathrm{cv}$ and $\mathrm{c}^{\prime \prime} \mathrm{v}^{\prime \prime} \subseteq \mathrm{cv}$ and demonstrate that $\mathrm{c}^{\prime} \mathrm{v}^{\prime} \subseteq \mathrm{c}^{\prime \prime} \mathrm{v}^{\prime \prime}$ or $\mathrm{c}^{\prime \prime} \mathrm{v}^{\prime \prime} \subseteq$ $\mathrm{c}^{\prime} \mathrm{v}^{\prime}$ as follows. We have from the definition of $\subseteq$ that $\mathrm{v}^{\prime} \leq \mathrm{v}, \mathrm{v}^{\prime \prime} \leq \mathrm{v}, \mathrm{c}^{\prime}=\{\mathrm{u}: \mathrm{u} \in \mathrm{c}$ and $\left.\mathrm{u} \leq \mathrm{v}^{\prime}\right\}$ and $\mathrm{c}^{\prime \prime}=\left\{\mathrm{u}: \mathrm{u} \in \mathrm{c}\right.$ and $\left.\mathrm{u} \leq \mathrm{v}^{\prime}\right\}$. When $\mathrm{c}$ is a past for $\mathrm{v}$, it follows that $\mathrm{v} \in \mathrm{c}$. Therefore, $\mathrm{v}^{\prime} \in \mathrm{c}^{\prime}$ and $\mathrm{v}^{\prime \prime} \in \mathrm{c}^{\prime \prime}$. It follows from $\mathrm{c}^{\prime}=\{\mathrm{u}: \mathrm{u} \in \mathrm{c}$ and $\left.\mathrm{u} \leq \mathrm{v}^{\prime}\right\}$ and $\mathrm{c}^{\prime \prime}=\left\{\mathrm{u}: \mathrm{u} \in \mathrm{c}\right.$ and $\left.\mathrm{u} \leq \mathrm{v}^{\prime \prime}\right\}$ that $\mathrm{v}^{\prime} \in \mathrm{c}$ and $\mathrm{v}^{\prime \prime} \in \mathrm{c}$. Since $\mathrm{c}$ is connected, it follows that $\mathrm{v}^{\prime} \leq \mathrm{v}^{\prime \prime}$ or $\mathrm{v}^{\prime \prime} \leq \mathrm{v}^{\prime}$. In the first case, it is possible to show that $\mathrm{c}^{\prime}=\left\{\mathrm{u}: \mathrm{u} \in \mathrm{c}^{\prime \prime}\right.$ and $\left.\mathrm{u} \leq \mathrm{v}^{\prime}\right\}$ from which it follows immediately that $\mathrm{c}^{\prime} \mathrm{v}^{\prime} \subseteq$ $\mathrm{c}^{\prime \prime} \mathrm{v}^{\prime \prime}$. To show that $\mathrm{c}^{\prime}=\left\{\mathrm{u}: \mathrm{u} \in \mathrm{c}^{\prime \prime}\right.$ and $\left.\mathrm{u} \leq \mathrm{v}^{\prime}\right\}$ simply show the following.

$$
\mathrm{u} \in \mathrm{c}^{\prime} \text { iff } \mathrm{u} \in \mathrm{c}^{\prime \prime} \& \mathrm{u} \leq \mathrm{v}^{\prime}
$$

The proof of this from right to left follows from $c^{\prime}=\left\{\mathrm{u}: \mathrm{u} \in \mathrm{c}\right.$ and $\left.\mathrm{u} \leq \mathrm{v}^{\prime}\right\}$ and $\mathrm{c}^{\prime \prime}=\left\{\mathrm{u}: \mathrm{u} \in \mathrm{c}\right.$ and $\left.\mathrm{u} \leq \mathrm{v}^{\prime \prime}\right\}$. For the other direction, use the same two facts, and $\mathrm{v}^{\prime} \leq \mathrm{v}^{\prime \prime}$. In case $\mathrm{v}^{\prime \prime} \leq \mathrm{v}^{\prime}$, it follows that $\mathrm{c}^{\prime \prime} \mathrm{v}^{\prime \prime} \subseteq \mathrm{c}^{\prime} \mathrm{v}^{\prime}$ by similar reasoning.

Lemma 2. If $\mathrm{v} \leq \mathrm{v}^{\prime}$ and $\mathrm{cv} \in \mathrm{W}$, then for some $\mathrm{c}^{\prime} \mathrm{v}^{\prime} \in \mathrm{W} \mathrm{cv} \subseteq \mathrm{c}^{\prime} \mathrm{v}^{\prime}$.

Proof. Suppose $\mathrm{v} \leq \mathrm{v}^{\prime}$ and $\mathrm{cv} \in \mathrm{W}$. Then $\mathrm{c}$ is a past for $\mathrm{v}$, hence $\mathrm{v} \in \mathrm{c}$, $\mathrm{c}$ is connected and for every $\mathrm{u} \in \mathrm{c}, \mathrm{u} \leq \mathrm{v}$. Let $\mathrm{c}^{\prime}=\mathrm{c}^{\prime \prime} \cup\left\{\mathrm{v}^{\prime}\right\}$. Then $\mathrm{c}^{\prime}$ is a past for $\mathrm{v}^{\prime}$, because $\mathrm{v}^{\prime} \in \mathrm{c}^{\prime}$ and for every $\mathrm{u} \in \mathrm{c}^{\prime}, \mathrm{u} \leq \mathrm{v}^{\prime}$, and $\mathrm{c}^{\prime}$ is connected. The reason that $\mathrm{c}^{\prime}$ is connected is that $\mathrm{cv} \in \mathrm{W}$ entails $\mathrm{c}$ is connected. The only additional member of $\mathrm{c}^{\prime}$ beyond the members of $\mathrm{c}$ is $\mathrm{v}^{\prime}$. But $\mathrm{u} \leq \mathrm{v}^{\prime}$ for all $\mathrm{u} \in \mathrm{c}^{\prime}$. Therefore adding $\mathrm{v}^{\prime}$ to the connected set $\mathrm{c}$ results in a new connected set $\mathrm{c}^{\prime}$. Set $\mathrm{c}$ is clearly $\left\{\mathrm{u}: \mathrm{u} \in \mathrm{c}^{\prime}\right.$ and $\mathrm{u} \leq \mathrm{v}\}$, so by the definition of $\subseteq, \mathrm{cv} \subseteq \mathrm{c}^{\prime} \mathrm{v}^{\prime}$, and $\mathrm{c}^{\prime} \mathrm{v}^{\prime}$ is the desired member of $\mathrm{W}$ such that $\mathrm{cv} \subseteq \mathrm{c}^{\prime} \mathrm{v}^{\prime}$.

Now we are ready to prove the Past Model Theorem.

Proof of the Past Model Theorem. To show that the frame $<\mathrm{W}, \subseteq>$ is reflexive, transitive, antisymmetric and obeys (No Past Branching), simply appeal to Lemma 1. The proof that $\mathrm{u}(\mathrm{cv}, \mathrm{A})=\mathrm{v}(\mathrm{A})$ for all wffs $\mathrm{A}$, and every past $\mathrm{c}$ for $\mathrm{v}$ is by structural induction on $\mathrm{A}$. The base case and the case for $\&$ are straightforward.

In the case of negations $\sim \mathrm{B}$ show $\mathrm{u}(\mathrm{cv}, \sim \mathrm{B})=\mathrm{v}(\sim \mathrm{B})$ by showing that the right hand side of $\|\sim\|$ and the right hand side of $\|\mathrm{u} \sim\|$ are equivalent given the 
hypothesis of the induction: $\mathrm{u}(\mathrm{cv}, \mathrm{B})=\mathrm{v}(\mathrm{B})$, for any member cv of W. So we must show $\|\sim\| \mathrm{r}$ iff $\|\mathrm{u} \sim\| \mathrm{r}$.

$$
\begin{gathered}
\|\sim\| \text { For all } \mathrm{v}^{\prime} \in \mathrm{V}, \text { if } \mathrm{v} \leq \mathrm{v}^{\prime} \text { then } \mathrm{v}^{\prime}(\mathrm{B})=\mathrm{f} \\
\|\mathrm{u} \sim\| \mathrm{r} \text { For all } \mathrm{w}^{\prime} \in \mathrm{W}, \text { if } \mathrm{cv} \subseteq \mathrm{w}^{\prime} \text { then } \mathrm{u}\left(\mathrm{w}^{\prime}, \mathrm{B}\right)=\mathrm{f} .
\end{gathered}
$$

For the proof from $\|\sim\| \mathrm{r}$ to $\|\mathrm{u} \sim\| \mathrm{r}$, assume $\mathrm{cv} \subseteq \mathrm{w}^{\prime}$ for any $\mathrm{w}^{\prime} \in \mathrm{W}$, and prove $\mathrm{u}\left(\mathrm{w}^{\prime}, \mathrm{B}\right)=\mathrm{f}$ as follows. Since $\mathrm{w}^{\prime} \in \mathrm{W}, \mathrm{w}^{\prime}=\mathrm{c}^{\prime} \mathrm{v}^{\prime}$ for some $\mathrm{v}^{\prime} \in \mathrm{V}$. Since $\mathrm{cv} \subseteq$ $\mathrm{c}^{\prime} \mathrm{v}^{\prime}, \mathrm{v} \leq \mathrm{v}^{\prime}$. Hence $\mathrm{v}^{\prime}(\mathrm{B})=\mathrm{f}$ by $\|\sim\| \mathrm{r}$. By the hypothesis of the induction, we have $\mathrm{u}\left(\mathrm{c}^{\prime} \mathrm{v}^{\prime}, \mathrm{B}\right)=\mathrm{f}$ as desired. For the other direction, assume $\mathrm{v} \leq \mathrm{v}^{\prime}$ and prove $\mathrm{v}^{\prime}(\mathrm{B})=\mathrm{f}$ as follows. We know $\mathrm{cv} \in \mathrm{W}$ and $\mathrm{v} \leq \mathrm{v}^{\prime}$, so by Lemma 2 , we have $\mathrm{cv} \subseteq \mathrm{c}^{\prime} \mathrm{v}^{\prime}$ for some member $\mathrm{c}^{\prime} \mathrm{v}^{\prime}$ of $\mathrm{W}$. From $\|\mathrm{u} \sim\| \mathrm{r}$, it follows that $\mathrm{u}\left(\mathrm{c}^{\prime} \mathrm{v}^{\prime}, \mathrm{B}\right)=\mathrm{f}$. The hypothesis of the induction yields $\mathrm{v}^{\prime}(\mathrm{B})=\mathrm{f}$ as desired.

The case for $\rightarrow$ is similar.

The case for disjunctions BvC will follow from showing that the following two conditions are equivalent, given the hypothesis of the induction.

$\|\mathrm{q} v\| \mathrm{r}$ For all $\mathrm{v}^{\prime} \in \mathrm{V}$, if $\mathrm{v} \leq \mathrm{v}^{\prime}$, then for some $\mathrm{v}^{\prime \prime} \in \mathrm{V}, \mathrm{v}^{\prime} \leq \mathrm{v}^{\prime \prime}$

and either $\mathrm{v}^{\prime \prime}(\mathrm{B})=\mathrm{t}$ or $\mathrm{v}^{\prime \prime}(\mathrm{C})=\mathrm{t}$.

$\|\mathrm{uqv}\| \mathrm{r}$ For all $\mathrm{w}^{\prime} \in \mathrm{W}$, if $\mathrm{cv} \subseteq \mathrm{w}^{\prime}$, then for some $\mathrm{w}^{\prime \prime} \in \mathrm{W}, \mathrm{w}^{\prime} \subseteq \mathrm{w}^{\prime \prime}$ and either $\mathrm{u}\left(\mathrm{w}^{\prime \prime}, \mathrm{B}\right)=\mathrm{t}$ or $\mathrm{u}\left(\mathrm{w}^{\prime \prime}, \mathrm{C}\right)=\mathrm{t}$.

For the proof from $\|\mathrm{qv}\| \mathrm{r}$ to $\|\mathrm{uqv}\| \mathrm{r}$, assume $\mathrm{cv} \subseteq \mathrm{w}^{\prime}$ for any $\mathrm{w}^{\prime} \in \mathrm{W}$, and show that for some $\mathrm{w}^{\prime \prime}$ such that $\mathrm{w}^{\prime} \subseteq \mathrm{w}^{\prime \prime}$, either $\mathrm{u}\left(\mathrm{w}^{\prime \prime}, \mathrm{B}\right)=\mathrm{t}$ or $\mathrm{u}\left(\mathrm{w}^{\prime \prime}, \mathrm{C}\right)=\mathrm{t}$ as follows. By the definition of $\mathrm{W}, \mathrm{w}^{\prime}=\mathrm{c}^{\prime} \mathrm{v}^{\prime}$ for some $\mathrm{v}^{\prime} \in \mathrm{V}$, and by $\mathrm{cv} \subseteq \mathrm{c}^{\prime} \mathrm{v}^{\prime}$, we obtain $\mathrm{v} \leq \mathrm{v}^{\prime}$. From $\|\mathrm{qv}\| \mathrm{r}$, it follows that for some $\mathrm{v}^{\prime \prime} \in \mathrm{V}, \mathrm{v}^{\prime} \leq \mathrm{v}^{\prime \prime}$ and $\mathrm{v}^{\prime \prime}(\mathrm{B})=\mathrm{t}$ or $\mathrm{v}^{\prime \prime}(\mathrm{C})=\mathrm{t}$. By Lemma 2, there is a member $\mathrm{c}^{\prime \prime} \mathrm{v}^{\prime \prime}$ of W such that $\mathrm{c}^{\prime} \mathrm{v}^{\prime} \subseteq \mathrm{c}^{\prime \prime} \mathrm{v}^{\prime \prime}$. By the hypothesis of the induction $u\left(c^{\prime \prime} v^{\prime \prime}, B\right)=t$ or $u\left(c^{\prime \prime} v^{\prime \prime}, C\right)=t$. So $c^{\prime \prime} v^{\prime \prime}$ is the desired $\mathrm{w}^{\prime \prime} \in \mathrm{W}$ such that $\mathrm{w}^{\prime} \subseteq \mathrm{w}^{\prime \prime}$ and either $\mathrm{u}\left(\mathrm{w}^{\prime \prime}, \mathrm{B}\right)=\mathrm{t}$ or $\mathrm{u}\left(\mathrm{w}^{\prime \prime}, \mathrm{C}\right)=\mathrm{t}$.

For the proof from $\|\mathrm{uqv}\| \mathrm{r}$ to $\|\mathrm{v}\| \mathrm{r}$, assume $\mathrm{v} \leq \mathrm{v}^{\prime}$, and find $\mathrm{a} \mathrm{v}^{\prime \prime}$ in $\mathrm{V}$ such that $\mathrm{v}^{\prime} \leq \mathrm{v}^{\prime \prime}$ and either $\mathrm{v}^{\prime \prime}(\mathrm{B})=\mathrm{t}$ or $\mathrm{v}^{\prime \prime}(\mathrm{C})=\mathrm{t}$ as follows. Since $\mathrm{cv} \in \mathrm{W}$, it follows from $\mathrm{v} \leq \mathrm{v}^{\prime}$ by Lemma 2 that for some $\mathrm{c}^{\prime} \mathrm{v}^{\prime}$ in $\mathrm{W}, \mathrm{cv} \subseteq \mathrm{c}^{\prime} \mathrm{v}^{\prime}$. By $\|\mathrm{uqv}\| \mathrm{r}$, there is a member $\mathrm{w}^{\prime \prime}$ of $\mathrm{W}$ such that $\mathrm{c}^{\prime} \mathrm{v}^{\prime} \subseteq \mathrm{w}^{\prime \prime}$ and either $\mathrm{u}\left(\mathrm{w}^{\prime \prime}, \mathrm{B}\right)=\mathrm{t}$ or $\mathrm{u}\left(\mathrm{w}^{\prime \prime}, \mathrm{C}\right)=\mathrm{t}$. Since $\mathrm{w}^{\prime \prime}$ must be $\mathrm{c}^{\prime \prime} \mathrm{v}^{\prime \prime}$ for some $\mathrm{v}^{\prime \prime} \in \mathrm{V}$, we have by the hypothesis of the induction that $\mathrm{v}^{\prime \prime}(\mathrm{B})=\mathrm{t}$ or $\mathrm{v}^{\prime \prime}(\mathrm{C})=\mathrm{t}$. We have $\mathrm{c}^{\prime} \mathrm{v}^{\prime} \subseteq \mathrm{c}^{\prime \prime} \mathrm{v}^{\prime \prime}$, so $\mathrm{v}^{\prime} \leq \mathrm{v}^{\prime \prime}$, hence $\mathrm{v}^{\prime \prime}$ is the desired valuation such that $\mathrm{v}^{\prime} \leq \mathrm{v}^{\prime \prime}$ and $\mathrm{v}^{\prime \prime}(\mathrm{B})=\mathrm{t}$ or $\mathrm{v}^{\prime \prime}(\mathrm{C})=\mathrm{t}$.

This completes the proof of the theorem.

\section{References}

Belnap, N. 1962. Tonk, plonk, and plink. Analysis 22: 130-134.

Belnap, N., M. Perloff, and M. Xu. 2001. Facing the future. New York: Oxford University Press. 
Belnap, N. 2005. Branching histories approach to indeterminism and free will. In Truth and probability, essays in honour of Hugues Leblanc, ed. B. Brown, and F. Lepage, 197-211. London: College Publishing.

Brown J.D.K., and J. Garson. The natural semantics of vagueness (in preparation).

Garson, J. 1990. Categorical semantics. In Truth or consequences, ed. M.J. Dunn, and A. Gupta, 155-175. Dordrecht: Kluwer.

Garson, J. 2001. Natural semantics. Theoria 67: 114-139.

Garson, J. 2013. What logics mean: from proof theory to model-theoretic semantics. Cambridge: Cambridge University Press.

Humberstone, L. 1981. From worlds to possibilities. Journal of Philosophical Logic 10: 313-339. Humberstone, L. 2011. The connectives. Cambridge: MIT Press.

Lyons, J. 1968. Introduction to theoretical linguistics. London: Cambridge University Press.

McCawley, J. 1993. Everything that linguists have always wanted to know about logic (but were ashamed to ask). Chicago: University of Chicago Press.

Taylor, R. 1962. Fatalism. The Philosophical Review 71: 56-66, also in Thinking about logic, ed. S. Cahn, R. Talise, and S. Aikin. Westview Press, Boulder, Colorado (Page numbers cited here are to the latter volume.).

Williamson, T. 1984. Vagueness. New York: Routledge.

van Fraassen, B. 1969. Presuppositions, supervaluations and free logic. In The logical way of doing things, ed. K. Lambert, 67-91. New Haven: Yale University Press. 